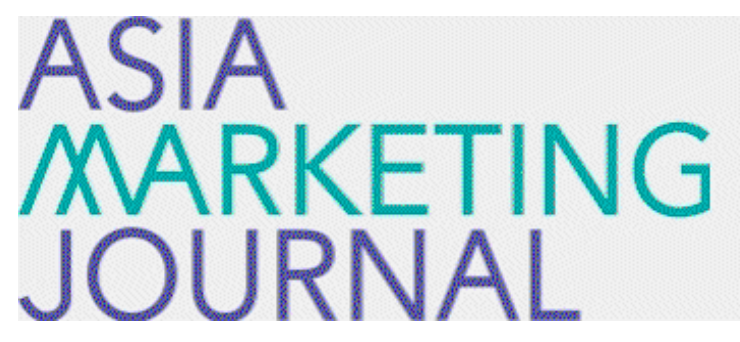

ASIA MARKETING JOURNAL

Volume 20 | Issue 3

Article 6

$10-31-2018$

\title{
ASIA MARKETING JOURNAL Vol.20 No.3 목차
}

Follow this and additional works at: https://amj.kma.re.kr/journal

Part of the Marketing Commons

\section{Recommended Citation}

(2018) "ASIA MARKETING JOURNAL Vol.20 No.3 목차," Asia Marketing Journal: Vol. 20 : Iss. 3 , Article 6. Available at: https://doi.org/10.53728/2765-6500.1319

This Article is brought to you for free and open access by Asia Marketing Journal. It has been accepted for inclusion in Asia Marketing Journal by an authorized editor of Asia Marketing Journal. 


\section{Vol. 20 No. 03 October 2018}

\section{<Research Paper>}

Differentiated B2B Marketing Strategy of Dongwon Systems, the No.1 Packaging Solution Company in Korea

- Mina Jun · Sang Yong Kim · Janghyuk Lee · Kay Ryung Koo 1

The Impact of Salesperson Look-Brand Personality Congruence on Brand Affect:

The Moderating Role of Social Anxiety

$$
\text { Heekyung Lee · Youjae Yi }
$$

Exploring Consumers' Alcoholic-Beverage Type-Specific Drinking Motives:

The Case of Young Adult Females in South Korea

Hyejeung Cho

The Dark Side of Star Marketing: Celebrity Endorsement Contracts Can Lower Consumers' Judgment of Brand Growth When the Firm is Tech-Focused Hojoon Jang $\cdot$ Kyoungmi Lee 63

Customer-Contact Employee Support and Service Recovery Efforts:

The Mediating Role of Job Burnout and Customer Orientation 